Volume 8. No. 1.2, 2020

International Journal of Emerging Trends in Engineering Research

Available Online at http://www.warse.org/IJETER/static/pdf/file/ijeter2181.22020.pdf

https://doi.org/10.30534/ijeter/2020/2181.22020

\title{
Influence of Recycled Concrete Aggregate (RCA) towards the Performance of Hot-Mix Asphalt (HMA) Mixture
}

\author{
Nurul Afikah Suratin ${ }^{1}$, Sk Muiz Sk Abd Razak ${ }^{1}$, Azlan Adnan ${ }^{2}$ \\ ${ }^{1}$ Department of Civil Engineering Technology, Universiti Malaysia Perlis, nurulafikahsuratin @ gmail.com, \\ skmuiz@unimap.edu.my \\ ${ }^{2}$ School of Civil Engineering, Faculty of Engineering, Universiti Teknologi Malaysia, azlanadnan@utm.my
}

\begin{abstract}
Significant use of Recycled Concrete Aggregate (RCA) has been applied by many countries especially in Hot-Mix Asphalt (HMA) as can possibly improve road construction in the economic and environmental aspects. However, in spite of such promising potentials, insufficient and inconclusive data to be referred based on previous study causes further study to be conducted as to focus more on the performance of aggregate in term of the impact and crushing value by using RCA. Also, to investigate the influence of different percentage $0 \%, 10 \%, 20 \%, 30 \%$ and $40 \%$ of RCA in the HMA mixture to the Marshall stability, flow value and water absorption. When the percentage of RCA content increase, the performance of all the parameters has become weaker and lowered. But then, RCA still can be used in the HMA as the differences in the performances with the natural aggregate is slightly small. Therefore, the optimum percentage of RCA got on this study is $30 \%$ by referred and discussed on all the five parameters. In conclusion, RCA is a great material that can be used to replace natural aggregate as it contributes great benefit in the environment aspect and also helps in the reduction of stockpiles of concrete wastes.
\end{abstract}

Key words: Aggregate Impact Value, Aggregate Crushing Value, Hot Mix Asphalt, Marshall Stability-Flow, Recycled Concrete Aggregate

\section{INTRODUCTION}

Aggregate is the main component of asphalt mixture; it composes about $98 \%$ of asphalt mix. The continuous use of natural aggregate is threatening the natural resources of it and especially it is known that the flexible pavement is one of the most worldwide pavement types. Therefore, the recycled of this material can protect the environment, provide sustainable construction and reduce demand on natural resources. Also, reduce the construction and production cost of new road [1].

Recycled concrete aggregate (RCA) has been successfully used in many paving applications, including new concrete paving mixtures for single or two lift concrete pavements, hot-mix asphalt paving mixtures, bound and unbound subbase applications, drainage layers and also as fill material [2]. The properties of RCA are different from those natural aggregate due to the mortar that attached to the RCA surface. Thus, the performance of Hot-mix asphalt (HMA) mixture made with RCA will be different from the natural aggregate [3].

As recycled concrete can be used within the same suburban area, it can lead to a decrease in the energy consumption related to transportation with a consequent improvement in the quality of air as a result of reducing the emissions of the mobile source and thus reducing the use of natural aggregate. The use of RCA in highway construction contributes in the reduction of consumption of natural aggregate and also elimination of the stockpiles of concrete wastes [4].

Many research studies have been conducted to evaluate the general engineering properties and performance of the RCA as unbound granular material in pavement construction. All the other has concluded the validity of the RCA as unbound granular material for base and subbase construction. However, only few studies were conducted on the use of RCA in the hot-mix asphalt (HMA) mixture [5]. Thus, this study will investigate the influence of using RCA as replacement of natural aggregate in HMA mixture towards the Marshall stability value, flow value, aggregate crushing value and aggregate impact value.

\section{LITERATURE REVIEW}

The engineering properties of RCA are different from natural aggregates due to remaining cement paste on their surfaces after the recycling process. The attached cement paste contributes to lower density, increase porosity and water absorption rate of RCA. Other than that, RCA can be good and economic alternative to fresh aggregate and can produce asphalt mixtures that withstand traffic load especially in light and medium traffic [6].

Coating the RCA with bitumen emulsion improves the water resistance due to the action of bitumen emulsion that making the RCA become obstructed, preventing the entry of water and therefore, improving the resistance of the mixture to moisture damage. Moreover, the bitumen emulsion achieves a better chemical affinity between the RCA and the bitumen, thereby preventing the mixture from stripping. 
Thus, coating treatment strengthen the mortar, preventing further fragmentation that could lead to the creation of new pathways for water. Also, the results of the tests of the resistance to permanent deformation indicate that HMA made with RCA exhibit good rutting performances that are similar to those of conventional mixtures. In conclusion, the fatigue life of HMA made with RCA coated with a bitumen emulsion is similar to that of conventional mixtures [8].

There are various studies that has been done regarding the usage of RCA as replacement of aggregate. Firstly, Pourtahmasb et al. [1] has carried out the Marshall Stability test on the HMA mixture by replacing the aggregate with RCA by five different percentages of $20 \%, 40 \%, 60 \%, 80 \%$ and $100 \%$. The stability values of HMA made with RCA contents from $0 \%$ up to $60 \%$ satisfied the standard design specifications which are more than $9.00 \mathrm{kN}$. Meanwhile, the stability value for $80 \%$ of RCA replacement does not comply with the standard design specifications.

Next, the flow values of HMA made with RCA contents from $0 \%$ up to $40 \%$ satisfied the standard design specifications which are between $2.00 \mathrm{~mm}$ to $4.00 \mathrm{~mm}$. Meanwhile, the flow value of RCA content from $60 \%$ and $80 \%$ replacement does not comply with the standard design specifications. Thus, the percentage of RCA used as replacement aggregate in the asphalt mixture can be up to $40 \%$ only as the result obtained from this study satisfied the standard design specifications for both stability and flow value.

Mostafa et al. [4] has carried out the Marshall Stability test on the HMA mixture by replacing the aggregate with RCA by five different percentages $(15 \%, 30 \%, 45 \%, 60 \%$ and $100 \%)$. The bitumen content use for this study is $5.5 \%$. The studied showed that the stability values of HMA made with RCA contents from $15 \%$ up to $60 \%$ satisfied the Egyptian specifications of stability value which are more than $7.1 \mathrm{kN}$. Meanwhile, the stability value for $100 \%$ of RCA replacement does not comply with the Egyptian specifications. Thus, the percentage of RCA used as replacement aggregate in the asphalt mixture can be up to $60 \%$ only as it is the limit that satisfied the Egyptian specifications.

Other than that, Panchal et al. [7] also have studied on the parameter of Marshall Stability and flow value of RCA when being used in HMA mixture. The percentage of usage of RCA used for this study is $100 \%$ as this study was to make a comparison between the usage of RCA and the conventional aggregate in the HMA mixture. Thus, the average Marshall stability and flow value got which are $9.10 \mathrm{kN}$ and $2.96 \mathrm{~mm}$ for this study are passing the standard design specification which is minimum of $8.2 \mathrm{kN}$ for Marshall Stability and range from $2 \mathrm{~mm}$ to $4 \mathrm{~mm}$ for flow value.

The Marshall Stability-Flow test on the asphalt mixture by replacing the natural aggregate with RCA. The percentages of RCA used for replacement of natural aggregate are by $5 \%$, $10 \%, 20 \%$ and $30 \%$. For this study, HMA made with RCA in percentages ranging from $0 \%$ to $30 \%$ comply with the specifications for traffic category of standard design $15 \mathrm{kN}$ for stability value and $2 \mathrm{~mm}$ for the flow value. Thus, by replacing natural aggregate with RCA up to $30 \%$ satisfied the road pavement standard design as a surface course layer [7].

\section{METHODOLOGY}

Research methodology comprises of the details of the samples and tests have been carried out in this study. For the first stage of methodology flow, the planning and selection of materials has been carried out. Then, classification of parameters. There are five parameters that has been carried out for this study which are Marshall stability, flow value, aggregate impact value, aggregate crushing value and water absorption rate.

Next is the determination of manipulated variable. Manipulated variable has been determined based on the correlation between the percentage changes of materials with the parameter measures. Lastly is the testing stage and tabulation of data for numerical analysis. It is done in order to find the optimum percentage of Recycle Concrete Aggregate (RCA) that can be used for the construction of surface layer of flexible pavement.

\subsection{Aggregate Preparation}

The materials selected to be tested for aggregate is Recycled Concrete Aggregate (RCA). The RCA used for this study has been collected from the laboratory's concrete cubes from quality control testing waste. Then, the RCA has been sieved passing the desired sieve size by following the standard mix designation of AC 14 which is for the wearing course layer, Malaysian Standard - JKR Arahan Teknik Jalan 5/85 as shown in Table 1 and then classified by the aggregate size as shown in Table 2.

Table 1: Malaysian gradation limits [9]

\begin{tabular}{|c|c|}
\hline Mix Designation & AC 14 \\
\hline Sieve Size $(\mathrm{mm})$ & Percentage passing by weight (\%) \\
\hline 20.0 & 100 \\
\hline 14.0 & $90-100$ \\
\hline 10.0 & $76-86$ \\
\hline 5.0 & $50-62$ \\
\hline 3.15 & $40-54$ \\
\hline 1.18 & $18-34$ \\
\hline 0.425 & $12-24$ \\
\hline 0.150 & $6-14$ \\
\hline 0.075 & $4-8$ \\
\hline
\end{tabular}

Table 2: The classification of aggregate size

\begin{tabular}{|c|c|}
\hline Aggregate Size & Passing sieve size $(\mathrm{mm})$ \\
\hline \multirow{3}{*}{ Large } & 20.0 \\
\cline { 2 - 2 } & 14.0 \\
\cline { 2 - 2 } Medium & 10.0 \\
\cline { 2 - 2 } & 5.0 \\
\hline \multirow{3}{*}{ Fine } & 3.15 \\
\cline { 2 - 2 } & 1.18 \\
\cline { 2 - 2 } & 0.425 \\
\cline { 2 - 2 } & 0.150 \\
\hline
\end{tabular}


After being sieved, the RCA then has been washed to remove the impurities on the surface of the RCA and then be air dried 24 hours.

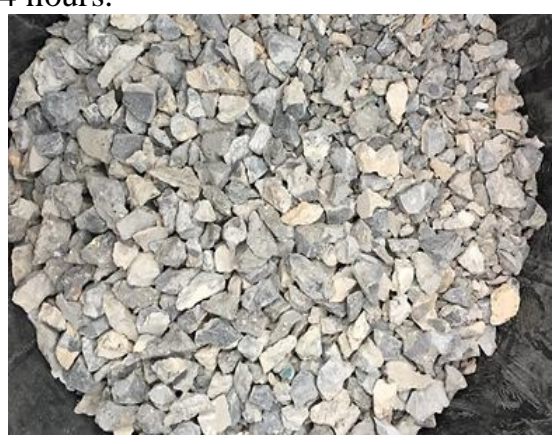

Figure 1: Recycled Concrete Aggregate before washing

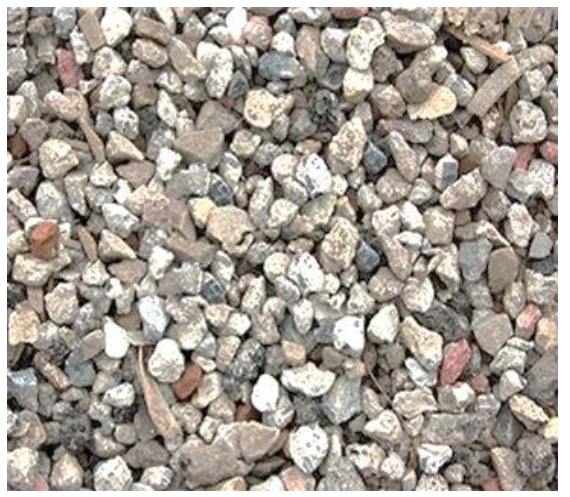

Figure 2: Recycled Concrete Aggregate after washing

\subsection{Sieve Analysis}

The grading of the aggregates that need to be used to construct a well graded asphalt mixture has complied with the standard mix designation as stated at Table 3. The standard mix designation that used in this study as the guide of the aggregate sizes is AC 14 [9]. The maximum size of aggregate used for this designation is $14 \mathrm{~mm}$ as it has to be $100 \%$ passed the sieve size of $20 \mathrm{~mm}$ and meanwhile, the minimum size of aggregate is $0.075 \mathrm{~mm}$. The testing of sieve analysis of aggregate has been carried out and tabulated in Table 3 .

Table 3: Gradation of Natural Aggregate based on Mix Design AC 14

\begin{tabular}{|c|c|c|c|c|c|}
\hline $\begin{array}{c}\text { Sieve } \\
\text { Sizes } \\
(\mathrm{mm})\end{array}$ & $\begin{array}{c}\text { Total } \\
\text { Weight } \\
(\mathrm{kg})\end{array}$ & $\begin{array}{c}\text { Weight } \\
\text { Passing } \\
(\mathrm{kg})\end{array}$ & $\begin{array}{c}\text { Percentage } \\
\text { passing } \\
(\%)\end{array}$ & $\begin{array}{c}\text { Upper } \\
\text { Limit } \\
(\%)\end{array}$ & $\begin{array}{c}\text { Lower } \\
\text { Limit } \\
(\%)\end{array}$ \\
\hline 20 & 7.83 & 90 & 100 & 100 & 100 \\
\hline 14 & 9.73 & 82.17 & 91.3 & 100 & 90 \\
\hline 10 & 21.75 & 72.44 & 80.49 & 86 & 76 \\
\hline 5 & 5.17 & 50.69 & 56.32 & 62 & 50 \\
\hline 3.15 & 19.85 & 45.52 & 50.58 & 54 & 40 \\
\hline 1.18 & 15.27 & 25.67 & 28.52 & 34 & 18 \\
\hline 0.425 & 3.34 & 10.4 & 11.56 & 24 & 12 \\
\hline 0.15 & 3.94 & 7.06 & 7.84 & 14 & 6 \\
\hline 0.075 & 3.12 & 3.12 & 3.47 & 8 & 4 \\
\hline pan & 0 & 0 & 0 & 0 & 0 \\
\hline
\end{tabular}

\section{PERCENTAGE PASSING AGAINST SIEVE SIZES}

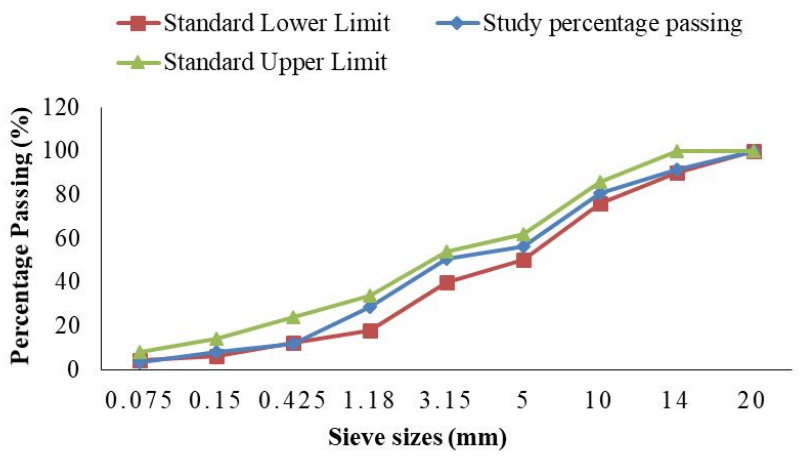

Figure 3: Graph of Natural Aggregate Gradation

The percentage passing of aggregates is then compared with the standard mix designation of upper limit and lower limit of standard grade. Subsequently, based on the grading curve of sieve analysis shown in Figure 3, the optimum percentage weight of aggregate to be used in the asphalt mixture was calculated. The aggregates are classified by the size and weight to be used in asphalt mixture as shown in Table 4.

Table 4: The classification of aggregate size based on the grading curve of sieve analysis

\begin{tabular}{|c|c|c|c|}
\hline $\begin{array}{c}\text { Aggregate } \\
\text { Size }\end{array}$ & $\begin{array}{c}\text { Passing sieve size } \\
(\mathrm{mm})\end{array}$ & $\begin{array}{c}\text { By Percentage } \\
(\%)\end{array}$ & $\begin{array}{c}\text { By } \\
\text { Weight } \\
(\mathrm{g})\end{array}$ \\
\hline \multirow{2}{*}{ Large } & 20.0 & \multirow{2}{*}{30} & $352.8 \mathrm{~g}$ \\
& 14.0 & & \\
\cline { 2 - 2 } & 10.0 & & \\
\hline \multirow{2}{*}{ Medium } & 5.0 & 50 & $588.0 \mathrm{~g}$ \\
\cline { 2 - 2 } & 3.15 & \multirow{2}{*}{20} & $235.2 \mathrm{~g}$ \\
\hline \multirow{2}{*}{ Fine } & 1.18 & \\
& 0.425 & & \\
\cline { 2 - 2 } & 0.150 & & \\
\cline { 2 - 2 } & 0.075 & & \\
\hline
\end{tabular}

The reason to done this sieve analysis and classified the aggregates based on it sizes is because the aggregates sizes to be mix in the asphalt will be well-blended and also there will be variation of sizes that will not allow any voids to be presented after being mixed.

\subsection{Aggregate Impact Value}

The procedure of the Aggregate Impact Value test been followed according to the standard method BS 812: Part 112: 1990 and MS 30: Part 10: 199. The way to done and operate the Aggregate Impact Value test are firstly, filled aggregates in the cylindrical measure and tamp the aggregate in 25 strokes with the tamping rod. Level the surface using tamping rod as a straight edge. The aggregate in the cylindrical measure then being weighted. This weight of the aggregate is used for the duplicate test on the same material. The 
aggregate being transferred from the cylindrical measure to the cup and compact the aggregate by tamping in 25 strokes with the tamping rod. The hammer then being released to fall freely on the aggregate. The test sample is subjected to a total of 15 blows. The aggregate sample from the cup being removed and weighted. The aggregate then being sieve through $2.36 \mathrm{~mm}$ sieve. Lastly, weighted and recorded the masses of the fractions passing and retained on the sieve.

Aggregate impact value test is the test that has been done on the aggregate only as to study the performance of the aggregate in term of impact value after being subjected to a sudden load on repeated times. The average AIV as shown in Table 5 and Figure 4 got for natural aggregate is $7.59 \%$ and meanwhile, for the RCA is $12.57 \%$. The average impact value got in this study for both the natural aggregate and RCA have passed the standard AIV design of 30\%.

Table 1: Summary of AIV results

\begin{tabular}{|c|c|c|c|c|c|c|c|}
\hline & \multicolumn{3}{|c|}{ Natural Aggregate } & \multicolumn{3}{|c|}{ RCA } & \multirow{2}{*}{$\begin{array}{c}\text { JKR } \\
\text { Stand } \\
\text { ard }\end{array}$} \\
\hline & A & B & $\mathrm{C}$ & A & B & $\mathrm{C}$ & \\
\hline $\begin{array}{l}\text { Mass of test } \\
\text { specimen, M1 } \\
(\mathrm{g})\end{array}$ & $\begin{array}{c}325 . \\
1\end{array}$ & $\begin{array}{c}320 . \\
0\end{array}$ & $\begin{array}{c}316 . \\
3\end{array}$ & $\begin{array}{l}27 \\
7.9\end{array}$ & $\begin{array}{c}257 \\
.4\end{array}$ & $\begin{array}{c}269 \\
.4\end{array}$ & \multirow{5}{*}{$<30 \%$} \\
\hline $\begin{array}{c}\text { Mass of } \\
\text { material } \\
\text { passing } \\
2.00 \mathrm{~mm} \text { test } \\
\text { sieve, M2 }(\mathrm{g})\end{array}$ & 26.4 & 21.8 & 24.8 & $\begin{array}{c}39 . \\
0\end{array}$ & $\begin{array}{c}29 . \\
2\end{array}$ & $\begin{array}{c}32 . \\
5\end{array}$ & \\
\hline $\begin{array}{c}\text { Mass of } \\
\text { material } \\
\text { retained } \\
2.00 \mathrm{~mm} \text { test } \\
\text { sieve, } \mathrm{M} 3(\mathrm{~g})\end{array}$ & $\begin{array}{c}297 . \\
4\end{array}$ & $\begin{array}{c}296 . \\
6\end{array}$ & $\begin{array}{c}286 . \\
9\end{array}$ & $\begin{array}{l}23 \\
3.8\end{array}$ & $\begin{array}{c}222 \\
.9\end{array}$ & $\begin{array}{c}236 \\
.5\end{array}$ & \\
\hline $\begin{array}{c}\text { AIV value } \\
(\%)\end{array}$ & 8.12 & 6.81 & 7.84 & $\begin{array}{c}14 . \\
0\end{array}$ & $\begin{array}{l}11 . \\
34 \\
\end{array}$ & $\begin{array}{l}12 . \\
06 \\
\end{array}$ & \\
\hline $\begin{array}{c}\text { Average AIV } \\
(\%)\end{array}$ & \multicolumn{3}{|c|}{7.59} & \multicolumn{3}{|c|}{12.47} & \\
\hline
\end{tabular}

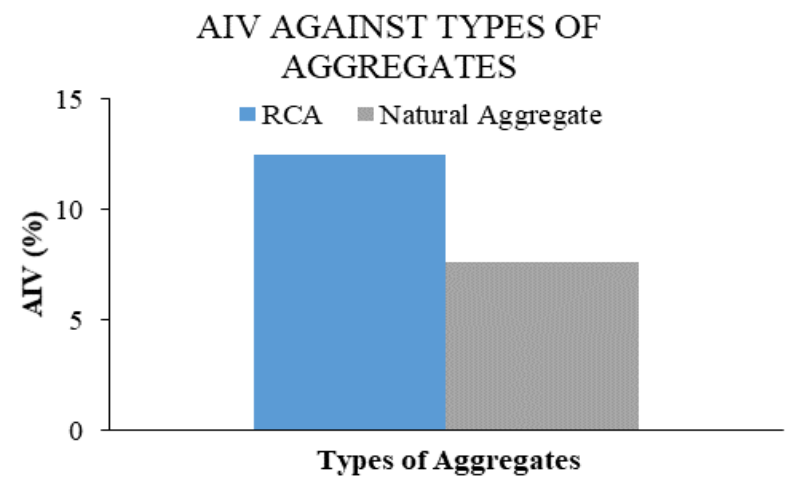

Figure 4: Comparison of average AIV result for Natural Aggregate and RCA

In conclusion, impact value of natural aggregate obtained in this study is slightly higher than natural aggregate. The differences of impact value between these two materials are not too large which is only $4.88 \%$. Therefore, can conclude that RCA can be used for the construction of asphalt mixture but in percentage range due to the reason that the aggregate recycled used are from the laboratory testing which the original concrete already has been tested and thus causing the concrete aggregate becomes weaker than the natural aggregate.

\subsection{Aggregate Crushing Value}

The procedure of the Aggregate Crushing Value test will be followed according to the standard method BS 812: Part 110: 1990 and MS 30: Part 8: 199. The way to done and operate the Aggregate Crushing Value test are firstly, filled the aggregates in the cylinder in three layers of approximately equal depth, each layer being subjected to 25 strokes from the tamping rod distributed evenly over the surface of the layer. The surface of the cylinder is then being levelled and the plunger will be inserted. The sample then will be placed between the platens of the testing machine and is loaded in a uniform rate so that the required $400 \mathrm{kN}$ is reached in 10 minutes. The load is then being released and the crushed material is removed. Weighted the mass of aggregate. The removed material is sieved on the $2.36 \mathrm{~mm}$ sieve and the weight of the fraction passing and retained on the sieve is recorded

Aggregate Crushing Value (ACV) test is the test that has been done on the aggregate only as to study the performance of the aggregate when the aggregates are subjected to a specified load under standardized conditions. The impact value obtained then being calculated the average ACV of it in the end and then being compared as shown in Table 6 and Figure 5. The average ACV got for natural aggregate is $16.58 \%$ and meanwhile, for the RCA is $28.78 \%$. The average crushing value got in this study for both the natural aggregate and RCA have passed the standard AIV design of $40 \%$.

Table 2: Summary of AIV results

\begin{tabular}{|c|c|c|c|c|c|c|c|}
\hline & \multicolumn{3}{|c|}{ Natural Aggregate } & \multicolumn{3}{|c|}{ RCA } & \multirow{2}{*}{$\begin{array}{c}\text { JKR } \\
\text { Standa } \\
\text { rd } \\
\end{array}$} \\
\hline & $\mathbf{A}$ & B & $\mathbf{C}$ & $\mathbf{A}$ & B & $\mathrm{C}$ & \\
\hline $\begin{array}{l}\text { Mass of test } \\
\text { specimen, M1 } \\
(\mathrm{g})\end{array}$ & $\begin{array}{l}242 \\
5.3\end{array}$ & $\begin{array}{l}220 \\
8.8\end{array}$ & $\begin{array}{c}324 \\
6.2\end{array}$ & $\begin{array}{l}230 \\
8.1\end{array}$ & $\begin{array}{l}240 \\
6.1\end{array}$ & $\begin{array}{l}228 \\
9.7\end{array}$ & \multirow[t]{2}{*}{-} \\
\hline $\begin{array}{c}\text { Mass of } \\
\text { material } \\
\text { passing } \\
2.00 \mathrm{~mm} \text { test } \\
\text { sieve, M2 }(\mathrm{g})\end{array}$ & $\begin{array}{c}362 . \\
21\end{array}$ & $\begin{array}{c}436 . \\
22\end{array}$ & $\begin{array}{c}488 . \\
87\end{array}$ & $\begin{array}{c}649 . \\
50\end{array}$ & $\begin{array}{c}638 . \\
33\end{array}$ & $\begin{array}{c}725 . \\
14\end{array}$ & \\
\hline $\begin{array}{c}\text { Mass of } \\
\text { material } \\
\text { retained } \\
2.00 \mathrm{~mm} \text { test } \\
\text { sieve, } \mathrm{M} 3(\mathrm{~g})\end{array}$ & $\begin{array}{l}206 \\
3.1\end{array}$ & $\begin{array}{l}177 \\
2.9\end{array}$ & $\begin{array}{l}275 \\
7.3\end{array}$ & $\begin{array}{l}165 \\
8.6\end{array}$ & $\begin{array}{l}176 \\
7.8\end{array}$ & $\begin{array}{l}156 \\
4.5\end{array}$ & \multirow{3}{*}{$\begin{array}{l}<40 \% \\
<40 \%\end{array}$} \\
\hline $\begin{array}{c}\mathrm{ACV} \text { value } \\
(\%)\end{array}$ & $\begin{array}{c}14.9 \\
3\end{array}$ & $\begin{array}{c}19.7 \\
5\end{array}$ & $\begin{array}{c}15.0 \\
6\end{array}$ & $\begin{array}{c}28.1 \\
4\end{array}$ & $\begin{array}{c}26.5 \\
3\end{array}$ & $\begin{array}{c}31.6 \\
7\end{array}$ & \\
\hline $\begin{array}{c}\text { Average ACV } \\
(\%)\end{array}$ & \multicolumn{3}{|c|}{16.58} & \multicolumn{3}{|c|}{28.78} & \\
\hline
\end{tabular}




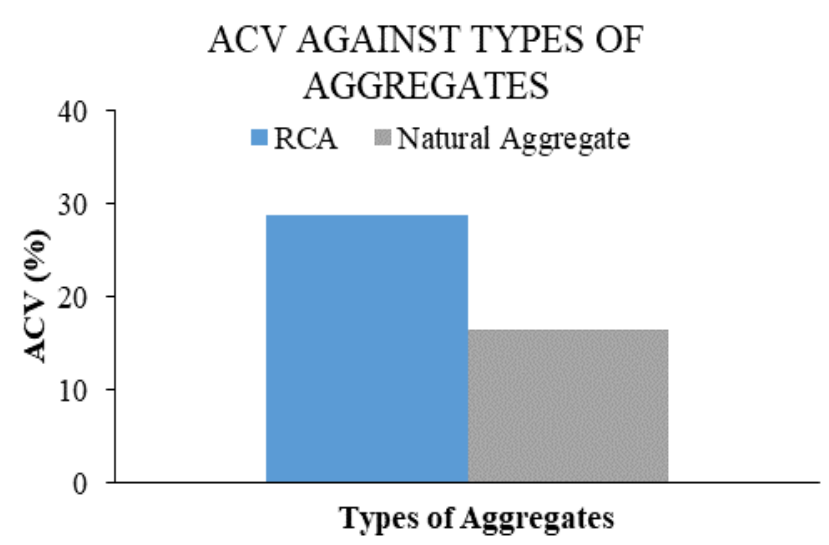

Figure 5: Comparison of average AIV result for Natural Aggregate and RCA

In conclusion, impact value of natural aggregate obtained in this study is slightly higher than natural aggregate. The differences of impact value between these two materials are not too large which is only $12.20 \%$. Therefore, can conclude that RCA can be used for the construction of asphalt mixture but in percentage range due to the reason that the aggregate recycled used are from the laboratory testing which the original concrete already has been tested and thus causing the concrete aggregate becomes weaker than the natural aggregate.

\subsection{Marshall Stability Value}

The procedure of the Marshall Stability-Flow test been followed according to the standard method ASTM D 1559-89. The way to done and operate the Marshall Stability-Flow test are firstly, he compaction mould assembly and rammer are cleaned and prepared by applying oil on the surface of the mould. The bitumen is then being heated to a temperature of $121^{\circ} \mathrm{C}$ to $130^{\circ} \mathrm{C}$. Then, pour the aggregate, mineral filler and bitumen in the mixer and thoroughly mixed all the materials until all particles are well coated. The mix is then being placed in a mould which is two pieces of filter papers are placed on the bottom of the mould. The specimen then being tamped 15 times on the surrounding of the steel mould and 10 times on the centre of the specimen by using tamping rod, then followed by placing another two pieces of filter paper on the surface of the specimen.

The steel mould being placed on the compaction pedestal in the mould holder and 75 blows with the compaction hammer are applied on both top and bottom surfaces of the specimen. The sample is then being taken out of the mould after few minutes using sample extractor and then immersed the specimen in the water bath at $60^{\circ} \mathrm{C}$ for 30 minutes. The specimen is then being removed from the water bath and the specimen surface is carefully dried before it is placed between the jaws of the specimen holder. The complete assembly has been placed in the compression testing machine and the flow meter is adjusted to 0 . The load being applied to the test specimen at a loading rate of $50.8 \mathrm{~mm} /$ minute until the maximum load is achieved. The Marshall Stability and Flow are then being recorded.

The first parameter that can be obtained from this Marshall stability-flow test is the Marshall Stability value. There are three samples constructed for each percentage and from these three sample readings, the average Marshall stability are calculated from it as shown in Table 7. The graph in Figure 6 shows that the Marshall stability obtained for all percentage of RCA has passed the standard design of $8.0 \mathrm{kN}$. But then, at the percentage content of $40 \%$ RCA, the Marshall stability is aligned with the standard design limit. Thus, can conclude that if there is more than $40 \%$ of RCA mixed with the natural aggregate in the asphalt mixture, the Marshall stability value obtained after that will be passing or exceeding the standard design limit of $8.0 \mathrm{kN}$.

Table 3: Summary of the Marshall Stability value

\begin{tabular}{|c|c|c|c|c|}
\hline $\begin{array}{c}\text { RCA } \\
\text { Percentage } \\
(\%)\end{array}$ & $\begin{array}{c}\text { NA } \\
\text { Percentage } \\
(\%)\end{array}$ & $\begin{array}{c}\text { Marshall } \\
\text { Stability } \\
(\mathrm{kN})\end{array}$ & $\begin{array}{c}\text { Average } \\
(\mathrm{kN})\end{array}$ & $\begin{array}{c}\text { JKR } \\
\text { Standard }\end{array}$ \\
\hline \multirow{3}{*}{0} & \multirow{3}{*}{100} & 15.404 & \multirow{3}{*}{19.454} & \multirow{15}{*}{$>8.0 \mathrm{kN}$} \\
\hline & & 21.869 & & \\
\hline & & 21.090 & & \\
\hline \multirow{3}{*}{10} & \multirow{3}{*}{90} & 15.526 & \multirow{3}{*}{15.713} & \\
\hline & & 15.404 & & \\
\hline & & 16.209 & & \\
\hline \multirow{3}{*}{20} & \multirow{3}{*}{80} & 12.404 & \multirow{3}{*}{13.192} & \\
\hline & & 13.962 & & \\
\hline & & 13.209 & & \\
\hline \multirow{3}{*}{30} & \multirow{3}{*}{70} & 11.890 & \multirow{3}{*}{11.177} & \\
\hline & & 9.080 & & \\
\hline & & 12.560 & & \\
\hline \multirow{3}{*}{40} & \multirow{3}{*}{60} & 9.025 & \multirow{3}{*}{8.194} & \\
\hline & & 7.760 & & \\
\hline & & 7.798 & & \\
\hline
\end{tabular}

\section{MARSHALL STABILITY AGAINST PERCENTAGE RCA CONTENT}

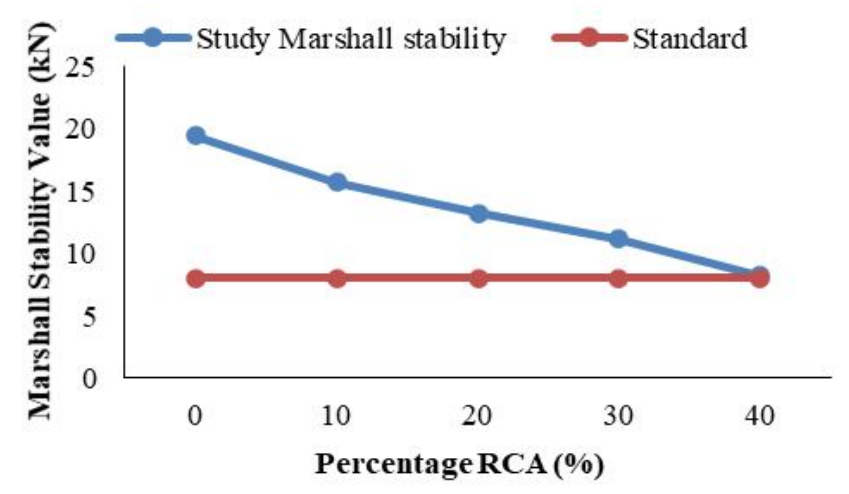

Figure 6: Marshall Stability $(\mathrm{kN})$ against Percentage RCA content $(\%)$ 


\subsection{Marshall Flow Value}

Next parameter that can be obtained from this Marshall stability-flow test is the flow value. The average Marshall stability are calculated from it as shown in Table 8 . The graph in Figure 7 shows that the Marshall flow value obtained for $0 \%, 10 \%, 20 \%$ and $30 \%$ of RCA have passed the standard design of $2-4 \mathrm{~mm}$. But then, at the percentage content of $40 \%$ RCA, the Marshall flow value is not passed the standard design limit. Thus, if the percentage of RCA content is higher than $30 \%$, the Marshall flow value are exceeding the standard design limit of maximum $4 \mathrm{~mm}$. Therefore, can conclude that the optimum percentage content of RCA to be used in the asphalt mixture based on the Marshall flow value is 30\%.

Table 4: Summary of the Marshall Flow Value

\begin{tabular}{|c|c|c|c|c|}
\hline $\begin{array}{c}\text { RCA } \\
\text { Percentag } \\
\mathrm{e} \\
(\%)\end{array}$ & $\begin{array}{c}\text { NA } \\
\text { Percentag } \\
\mathrm{e} \\
(\%)\end{array}$ & $\begin{array}{c}\text { Marshall } \\
\text { Flow } \\
\text { Value }(\mathrm{mm})\end{array}$ & $\begin{array}{c}\text { Average } \\
(\mathrm{mm})\end{array}$ & $\begin{array}{c}\text { JKR } \\
\text { Standar } \\
\text { d }\end{array}$ \\
\hline \multirow{3}{*}{0} & \multirow{3}{*}{100} & 1.569 & \multirow{3}{*}{1.916} & \multirow{15}{*}{$2-4 \mathrm{~mm}$} \\
\hline & & 2.045 & & \\
\hline & & 2.135 & & \\
\hline \multirow{3}{*}{10} & \multirow{3}{*}{90} & 3.420 & \multirow{3}{*}{3.231} & \\
\hline & & 3.005 & & \\
\hline & & 3.269 & & \\
\hline \multirow{3}{*}{20} & \multirow{3}{*}{80} & 3.677 & \multirow{3}{*}{3.541} & \\
\hline & & 3.540 & & \\
\hline & & 3.405 & & \\
\hline \multirow{3}{*}{30} & \multirow{3}{*}{70} & 3.778 & \multirow{3}{*}{3.873} & \\
\hline & & 3.963 & & \\
\hline & & 3.879 & & \\
\hline \multirow{3}{*}{40} & \multirow{3}{*}{60} & 4.184 & \multirow{3}{*}{4.399} & \\
\hline & & 4.459 & & \\
\hline & & 4.555 & & \\
\hline
\end{tabular}

\section{MARSHALL FLOW VALUE AGAINST PERCENTAGE RCA CONTENT}

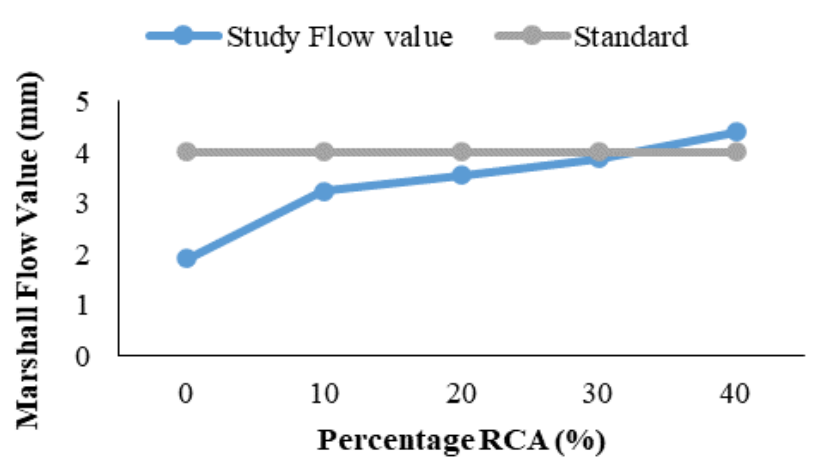

Figure 7: Marshall Flow (mm) against Percentage RCA content (\%)

In conclusion, if compare result obtained from this study with previous study, the Marshall stability and flow value determined in this study is in range with the previous study for the RCA. However, the value of RCA that this study determined have been stated more clearly than the previous study as Marshall stability and flow value is from the recycled of concrete laboratory testing which the original concrete already has been tested and thus causing the concrete aggregate becomes weaker than the other recycled concrete.

\subsection{Water Absorption}

The procedure of the Aggregate Crushing Value test been followed according to the standard method MS 30: Part 9. The way to done and operate the Aggregate Crushing Value test are firstly, the material being dried. Drying should occur in an oven regulated at $230^{\circ} \mathrm{F}\left(110^{\circ} \mathrm{C}\right)$. Then, aggregate being cooled to a comfortable handling temperature. The aggregate being immersed in water at room temperature for a period of 24 hours. The sample being removed from the water. Roll it in a towel cloth until all visible films of water are removed. The sample is in saturated surface dry (SSD) condition. The sample being weighted to obtained saturated surface dry weight, B (g). SSD sample being placed in the wire basket and determine its weight in water: $\mathrm{C}(\mathrm{g})$. The sample being removed from the wire basket. The sample being dried to constant weight at a temperature of $110 \pm 5^{\circ} \mathrm{C}$ (approximately $24 \mathrm{~h}$ ), and weigh: A (g). Lastly, absorption rate of aggregate has been calculated and tabulated.

Some of the samples are mixed with these two materials of natural aggregate and RCA by percentage. There are three samples constructed for each percentage and from these three sample readings, the average Marshall stability are calculated from it as shown in Table 9. The graph in Figure 8 shows that the water absorption obtained for all percentage of RCA has passed the standard design of lower than $2.0 \%$. Thus, can conclude that if there even up until $40 \%$ of RCA mixed with the natural aggregate in the asphalt mixture, the water absorption obtained has passed the standard design limit of $2.0 \%$.

Table 5: Summary of water absorption

\begin{tabular}{|c|c|c|c|c|}
\hline $\begin{array}{c}\text { RCA } \\
\text { Percentag } \\
\text { e } \\
(\%) \\
\end{array}$ & $\begin{array}{c}\text { NA } \\
\text { Percentage } \\
(\%)\end{array}$ & $\begin{array}{c}\text { Water } \\
\text { Absorption }(\%)\end{array}$ & $\begin{array}{c}\text { Average } \\
(\%)\end{array}$ & $\begin{array}{c}\text { JKR } \\
\text { Standar } \\
\text { d }\end{array}$ \\
\hline \multirow{3}{*}{0} & \multirow{3}{*}{100} & 0.220 & \multirow{3}{*}{0.290} & \multirow{15}{*}{$<2 \%$} \\
\hline & & 0.268 & & \\
\hline & & 0.381 & & \\
\hline \multirow{3}{*}{10} & \multirow{3}{*}{90} & 0.674 & \multirow{3}{*}{0.773} & \\
\hline & & 0.806 & & \\
\hline & & 0.840 & & \\
\hline \multirow{3}{*}{20} & \multirow{3}{*}{80} & 1.361 & \multirow{3}{*}{1.252} & \\
\hline & & 1.129 & & \\
\hline & & 1.266 & & \\
\hline \multirow{3}{*}{30} & \multirow{3}{*}{70} & 1.509 & \multirow{3}{*}{1.540} & \\
\hline & & 1.480 & & \\
\hline & & 1.632 & & \\
\hline \multirow{3}{*}{40} & \multirow{3}{*}{60} & 1.805 & \multirow{3}{*}{1.767} & \\
\hline & & 1.765 & & \\
\hline & & 1.730 & & \\
\hline
\end{tabular}




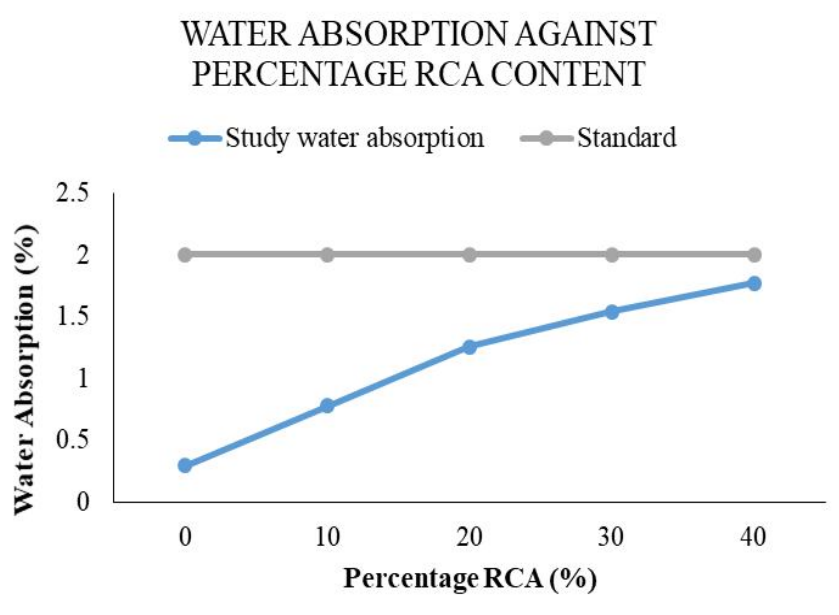

Figure 8: Water absorption (\%) against Percentage RCA content $(\%)$

In conclusion, if compare result obtained from this study with previous study as shown in Table 9, the water absorption determined in this study is slightly higher than most previous study for the RCA. However, the value of RCA that this study determined have been stated more clearly than the previous study as water absorption has been determined is in the form of mixture rather than aggregate form and also the aggregate is from the recycled of concrete laboratory testing which the original concrete already has been tested and thus causing the concrete aggregate becomes weaker than the natural aggregate.

\section{CONCLUSION}

In this study, the influence of different percentages of RCA in HMA has been successfully carried out and the objectives have been achieved. The objectives also have been achieved through the four different type of tests that uses different percentages of RCA as the replacement of natural aggregate.

The performance of RCA has been observed and assessed. Both the aggregate impact value (AIV) and aggregate crushing value (ACV) of RCA, which are $12.57 \%$ and $28.78 \%$ respectively achieved the targeted values based on AC 14, which are less than $30 \%$ for AIV and less than $40 \%$ for ACV. Thus, the RCA can effectively be used as partial replacement of natural aggregates in HMA for the purpose of road and pavement construction.

Other than that, the influence of different percentage of RCA in the HMA mixture to the Marshall Stability value, flow value and water absorption has also been investigated. The presence of RCA in the HMA bring significant effect towards the Marshall Stability value, flow value and water absorption. The reason for this finding is because the RCA used in this study is obtained by recycling the concrete waste from laboratory testing. These are the original concrete that already has been tested and thus causing the concrete aggregate becomes weaker than the natural aggregate.

Lastly, the optimum percentage content of RCA also has been obtained at the end of the findings. As a conclusion, the optimum percentage content of RCA that can be used in the
Hot-Mix Asphalt (HMA) mixture is $30 \%$ as it passed all the standard design limit for all parameters of aggregate impact value, aggregate crushing value, Marshall stability value, flow value and water absorption.

\section{ACKNOWLEDGEMENT}

The authors are grateful to the University Malaysia Perlis for giving the opportunity to write and complete the research. The authors also would like to thank the Department of Civil Engineering Technology for supplying the natural aggregate and also the recycled concrete aggregate material. Also, many thanks to the Pens Industries Sdn. Bhd. For providing asphalt binder. Their kind assistance is greatly appreciated.

\section{REFERENCES}

1. M. S. Pourtahmasb and M. R. Karim, Performance evaluation of stone mastic asphalt and hot mix asphalt mixtures containing recycled concrete aggregate, Advances in Materials Science and Engineering, vol. 2014, 2014.

2. M. B. Snyder, Concrete pavement recycling and the use of recycled concrete aggregate in concrete paving mixtures, CP Road Map, 2016.

3. A. R. Pasandín, I. Pérez, J. R. M. Oliveira, H. M. R. D. Silva, and P. A. A. Pereira, Influence of ageing on the properties of bitumen from asphalt mixtures with recycled concrete aggregates, Journal of Cleaner Production, vol. 101, pp. 165-173, 2015.

4. N. Mohammed, K. Sarsam, and M. Hussien, The influence of recycled concrete aggregate on the properties of concrete, in MATEC Web of Conferences, vol. 162, p. 2020, 2018.

5. D. El-Tahan, A. Gabr, S. El-Badawy, and M. Shetawy, Evaluation of recycled concrete aggregate in asphalt mixes, Innovative Infrastructure Solutions, vol. 3, no. 1, p. 20, 2018.

6. M. Noufal and Z. Maalla, Reuse Waste Plastic and Concrete Aggregate in Production of Hot Mix Asphalt, Imperial Journal Of Interdisciplinary Research, vol. 2, no. 7, pp. 1442-1444, 2016.

7. Panchal, Vishal V, Vinayak B Kulkarni, Avadhut Kulkarni, and Akash Kumar, Use of Construction Demolition Waste in Pavement, International Journal of Advanced Research in Science, Engineering and Technology 4(12): 4956-64, 2017.

8. Pérez, I., and A. R. Pasandín, Moisture Damage Resistance of Hot-Mix Asphalt Made with Recycled Con-crete Aggregates and Crumb Rubber, Journal of Cleaner Production 165: 405-14.M, 2017.

9. Manual of The Structural Design of Flexible Pavement, -ATJ 5_85 (Pind 2013), 2013. 